\title{
Produção e qualidade de frutos de melões amarelo e charentais cultivados em ambientes sombreados
}

\author{
Francisco H. F. Pereira ${ }^{1}$, Mário Puiatti ${ }^{2}$, Fernando L. Finger ${ }^{2}$, Paulo R. Cecon ${ }^{2} \&$ Leonardo A. de Aquino ${ }^{3}$
}

\section{RESU MO}

O bjetivou-se, neste estudo, avaliar a produção e a qualidade de frutos de melões, tipos Amarelo ('Gold M ine') e Charentais ('Fleuron'), em experimento conduzido na Universidade Federal de Viçosa, no período de 24/11/2003 a 11/03/ 2004. Os tratamentos foram constituídos de quatro ambientes de cultivo: Controle (pleno sol) e sob sombreamento com malhas Aluminet ${ }^{\circledR 3}$ 30\%-0, Cromatinet ${ }^{\circledR} 30 \%-0$ e Sombrite ${ }^{\circledR 3}$, $\%$. 0 delineamento experimental foi 0 inteiramente casualizado, com quatro repetições. Dentre os tratamentos com sombreamento a mal ha Aluminet ${ }^{\circledR} 30 \%-0$ foi 0 que mais se destacou não diferindo em produção nem em qualidade, de frutos do tratamento sob condições de pleno sol. Fatores climáticos registrados em cada ambiente de cultivo e genéticos inerentes aos híbridos 'Gold Mine' (Grupo Inodorus) e 'Fleuron' (Grupo Cantaloupensis) interferiram na produção e na qualidade dos frutos de melão. A baixa insolação média diária, a radiação fotossinteticamente ativa moderada e a elevada precipitação pluviométrica registrada ao longo do experimento contribuíram para a redução na qualidade dos frutos. 0 desempenho satisfatório das plantas sob a malha Aluminet ${ }^{\circledR} 30 \%-0$ possibilita o cultivo do meloeiro em sistemas agroflorestais ou cultivos associados.

Palavras-chave: Cucumis melo, sombreamento, produtividade, sólidos solúveis totais, etileno

\section{Yield and quality of yellow and "charentais" melon fruits cultivated in shaded environments}

\begin{abstract}
This work aimed to evaluate the yield and quality of melon fruits, types Yellow (Gold Mine) and "Charentais" (Fleuron), in an experiment carried out at the U niversidade Federal de Viçosa, from 11/24/2003 to 03/11/2004. The treatments were constituted of four cultivation environments: control (full sun) and shaded with screens Aluminet ${ }^{\circledR} 30 \%-0$, Cromatinet $^{\circledR}$ 30\%-0 and Sombrite ${ }^{\circledR} 30 \%$. The experiment was disposed in a completely randomized design, with four replicatios. Among the treatments with shading the screen Aluminet ${ }^{\circledR} 30 \%$. 0 was the one that most stood out, not having differences in yield and quality of fruits from those obtained under conditions of full sun. The climatic factors registered in each cultivation environment and the inherent genetic factors to the hybrid Gold M ine (Inodorus group) and Fleuron (Cantaloupensis group) also interfered in the yield and quality of the melon fruits. The low daily medium sunshine, the moderate photosynthetic active radiation and the high precipitation registered along the experiment contributed to the reduction in the quality of the fruits. The good performance of the melon plant, when cultivated under Aluminet ${ }^{\circledR} 30 \%-0$ screen, opens perspectives for agroforest systems or associated cultivations.
\end{abstract}

Key words: Cucumis melon, shading, yield, total soluble solids, ethylene

${ }_{1}^{1}$ CCTA/UFCG, Campus Pombal, Rua João Leite, 517, Centro, CEP 5884-000, Pombal, PB. Fone: (83) 3431-2211. E-mail: fhfpereira@hotmail.com

2 Departamento de Fitotecnia/UFV, Av. P. H. Rolfs s/n, CEP 36570-000, Viçosa, MG. Fone: (31) 3899-1171. E-mail: mpuiatt@ @ufv.br; ffinger@ufv.br; cecon@ufv.dpi.br 3 IFET Norte de Minas, Campus Januária, Fazenda São Geraldo s/n, CEP 39480-000, Januária, M G. Fone: (38) 3621-1100. E-mail: aquinoufv@yahoo.com.br 


\section{INTRODUÇÃO}

A síntese de assimilados e seu acúmulo nos frutos são as etapas mais importantes na determinação da produção e da qualidade do melão (Burger et al., 2000). São frutos controlados por complexas relações fonte-dreno que envolvem todos os órgãos da planta. Essas relações incluem o metabolismo e o particionamento de assimilados na folha-fonte, a subsequente translocação e particionamento entre os vários drenos e, finalmente, o metabolismo no próprio fruto, que determina o destino dos assimilados importados (Schaffer et al., 1996). Os processos de maturação e amadurecimento dos frutos também envolvem complexas alterações fisiológicas e bioquímicas, como mudanças nos níveis hormonais, na atividade respiratória, na atividade enzimática, na organização celular, no amaciamento da polpa e no sabor, atribuídas à síntese de compostos aromáticos, ácidos orgânicos e açúcares solúveis. Todas essas alterações são dependentes do genótipo e das condições climáticas ambientais, principalmente durante as fases de maturação e amadurecimento dos frutos de melão (Villanueva et al., 2004).

A radiação solar é a fonte primária de energia responsável pela manutenção do processo fotossintético. Por meio da fase fotoquímica da fotossíntese as plantas convertem a energia física da luz solar em energia química, processo este essencial para a fase carboxilativa da fotossíntese responsável pela fixação de $\mathrm{CO}_{2}$ e síntese de fotoassimilados destinados à manutenção do crescimento e produção das plantas (Taiz \& Zeiger, 2004). A baixa radiação solar limita o crescimento das plantas, a produção e a qualidade dos frutos, por lhes restringir a disponibilidade de fotoassimilados (Nishizawa et al., 1998; Andriolo, 2000). No entanto, a radiação solar excessiva, acima do ponto de saturação luminoso, também pode ser prejudicial à fotossíntese em razão de danos ao aparato fotossintético e, quando associada a elevadas temperaturas, pode favorecer a transpiração excessiva levando à redução do potencial hídrico na folha, o que resulta em fechamento estomático e redução na captação do $\mathrm{CO}_{2}$ pelas plantas (Andriolo, 2000). Em melões Cantaloupe e Honey Dew tem-se constatado que o ponto de saturação luminoso é atingido entre 1.000 e $1.200 \mu \mathrm{mol} \mathrm{m} \mathrm{m}^{-2} \mathrm{~s}^{-1}$ (Kitroongruang et al., 1992). Esta faixa está, portanto, bem abaixo da radiação incidente nas condições tropicais a qual pode atingir valores superiores a $1.800 \mu \mathrm{mol} \mathrm{m}{ }^{-2} \mathrm{~s}^{-1}$ (Nakansah et al., 1996).

Tem-se estudado, em alguns trabalhos, os efeitos do sombreamento, sobretudo durante o período de crescimento e a maturação dos frutos de melão, através da investigação das mudanças nos atributos de produção e qualidade desses frutos. Nishizawa et al. (1998) verificaram que o sombreamento não exerceu efeito na massa média dos frutos; todavia, o acúmulo de sacarose durante o processo de maturação lhe foi menor atribuindo, como responsável por esta redução, a escassez no suprimento de fotassimilados pelas folhas-fonte em plantas sombreadas. Nishizawa et al. (2000), também observaram que o sombreamento durante a fase de crescimento e maturação dos frutos de melão reduziu a firmeza da polpa, a concentração de substâncias insolúveis em álcool e o acúmulo de açúcares solúveis mas aumentou o teor de água no fruto e a liberação de etileno, concluindo-se que a radiação solar exerce papel fundamental durante o processo de maturação do fruto.

Combrink et al. (1995) verificaram que o estádio de amadurecimento em frutos de melão foi reduzido sob condições de pleno sol diminuindo, com isto, o período de desenvolvimento e a concentração de sólidos solúveis, quando comparados a frutos de melão sombreados. Evidenciaram, ainda, que frutos de melão sombreados são menos suscetíveis à injúria por frio e apresentam maior firmeza da polpa quando submetidos a condições de armazenamento refrigerado. Pelos resultados concluíram que condições de manejo da cultura que prolongam o período de amadurecimento e acúmulo de fotoassimilados no fruto são importantes na obtenção de frutos de melhor qualidade em virtude dos mesmos não acumularem amido e, portanto, dependem de suprimento externo de açúcares solúveis quando ainda na planta, para melhoria de sua qualidade.

Ante o exposto se propôs, neste trabalho, avaliar a produção e a qualidade de frutos de melões tipos Amarelo, híbrido 'Gold Mine' e Charentais, híbrido 'Fleuron', cultivados sob proteção com diferentes malhas.

\section{MATERIAL E METODOS}

O experimento foi conduzido na Horta de Pesquisas do Departamento de Fitotecnia da Universidade Federal de Viçosa, no período de 24/11/2003 a 11/03/2004. Utilizaram-se os híbridos de melão 'Gold Mine' (Grupo Inodorus) e 'Fleuron' (Grupo Cantaloupensis), cultivados em solo classificado como Argissolo Vermelho-Amarelo, Câmbico, fase terraço, textura argilosa. Os resultados médios das análises químicas antes da instalação do experimento, foram: $\mathrm{pH}$ em $\mathrm{H}_{2} \mathrm{O}(1: 2,5)=5,8 ; \mathrm{P}=58,5 ; \mathrm{K}=76,0 \mathrm{mg} \mathrm{dm}^{-3} ; \mathrm{Ca}=4,0 ;$ $\mathrm{Mg}=0,8 ; \mathrm{Al}=0,0 ; \mathrm{H}+\mathrm{Al}=3,63 ; \mathrm{SB}=4,99 ; \mathrm{CTC}_{\text {efetiva }}=$ 4,99; $\mathrm{CTC}_{\text {total }}=8,62 \mathrm{cmol}_{\mathrm{c}} \mathrm{dm}^{-3}$ e M.O. $=3,33 \mathrm{dag} \mathrm{kg}^{-1}$. As variáveis climáticas registradas durante a condução do experimento se encontram na Tabela 1.

As temperaturas do ar, do solo e a umidade relativa do ar, foram medidas diariamente durante a condução do experimento, utilizando-se termohigrometro digital modelo

Tabela 1. Dados climáticos coletados durante a condução do experimento sob condições de pleno sol (controle - $\mathrm{CO}$ ) e nos ambientes sob as malhas Aluminet ${ } 30 \%-0$ - (AL), Cromatinet ${ }^{\circledR}$ 30\%-0 (CR) e Sombrite $® 30 \%$ (SO)

\begin{tabular}{llcccc}
\hline Variáveis climáticas & & C0 & AL & \multicolumn{1}{c}{ CR } & \multicolumn{1}{c}{ S0 } \\
Temperatura do ar $\left({ }^{\circ} \mathrm{C}\right.$ ) & Mín & 17,58 & 18,17 & 17,74 & 18,28 \\
& Máx & 33,40 & 32,41 & 31,67 & 33,14 \\
& Mín & 23,47 & 22,31 & 22,55 & 22,68 \\
Temperatura do solo ( ${ }^{\circ} \mathrm{C}$ ) & Máx & 24,20 & 23,11 & 23,35 & 23,38 \\
& Mín & 45,30 & 49,24 & 49,72 & 49,76 \\
UR do ar (\%) & Máx & 80,43 & 87,25 & 86,79 & 88,24 \\
& & 775,93 & 536,95 & 497,37 & 527,37 \\
RFA ( $\mu$ mol m-2 s $\left.^{-1}\right)^{1}$ & & 4,47 & 4,47 & 4,47 & 4,47 \\
Insolação média diária (h) & & 1.027 & 1.027 & 1.027 & 1.027 \\
Precipitação (mm) & & & & &
\end{tabular}

1RFA - radição fotossinteticamente ativa 
HT-208 (ICEL-Manaus). A RFA também foi medida diariamente, em três diferentes épocas, durante a condução do experimento, com o Ceptômetro modelo SF-80 (Delta-T Devices, LTD). A insolação média diária foi medida na estação meteorológica da Universidade Federal de Viçosa, localizada próximo à área experimental. A precipitação pluvial foi medida em pluviômetro, com dimensões de $9,7 \mathrm{~cm}$ de diâmetro e $40 \mathrm{~cm}$ de comprimento, instalado na área experimental.

Os tratamentos se constituíram de quatro ambientes de cultivo: Controle (pleno sol) e sob as malhas Aluminet ${ }^{\circledR}$ $30 \%-O$, Cromatinet ${ }^{\circledR} 30 \%-\mathrm{O}$ e Sombrite ${ }^{\circledR} 30 \%$, essas com reduções na RFA em 30,8, 35,9 e 32,0\%, respectivamente. As malhas foram instaladas em "telados" com dimensões de $2 \times 4 \times 36$ m (altura, largura e comprimento), mantendo-se as laterais abertas, na altura de $1,5 \mathrm{~m}$, para permitir acesso dos insetos polinizadores (abelhas melíferas). O delineamento experimental utilizado foi o inteiramente casualizado, com quatro repetições.

O preparo do solo constou de aração, gradagem, abertura de sulcos de plantio espaçados 1,0 m, seguido da adubação de plantio e elevação de canteiros com altura de $0,20 \mathrm{~m} \mathrm{e}$ largura de $0,40 \mathrm{~m}$. A adubação de plantio, baseada na análise de solos e recomendações para a cultura do meloeiro (Silva \& Costa, 2003), foi aplicada nos sulcos e constou $\left(\mathrm{kg} \mathrm{ha}^{-1}\right)$ de: 240 de $\mathrm{P}_{2} \mathrm{O}_{5} ; 19,0$ de $\mathrm{K}_{2} \mathrm{O}$ (10\% do total), 15,0 de $\mathrm{N}(10 \%$ do total), 200 de sulfato de magnésio; 20 de bórax; 15 de sulfato de zinco e 3,0 $\mathrm{kg} \mathrm{ha}^{-1}$ de molibidato de amônio, os quais foram distribuídos e misturados dentro dos sulcos. Durante o ciclo da cultura e juntamente com a água de irrigação (fertirrigação), adubações complementares de cobertura foram feitas com $\mathrm{N}$ e K, iniciando-se aos sete dias após o transplante. Aplicaram-se 135,0 kg de N + 171,0 kg de $\mathrm{K}_{2} \mathrm{O}$ ha $^{-1}$, divididos em dez aplicações semanais, obedecendo aos seguintes critérios: $5,0 \%$ da quantidade de cada elemento nas duas primeiras semanas e $10 \%$ a cada semana, até os 70 dias do transplante.

A semeadura foi realizada em 24/11/2003, em bandejas de polipropileno expandido de 128 células, preenchidas com substrato comercial, colocando-se uma semente por célula, mantidas em ambiente protegido. Efetuou-se o transplante quando as mudas apresentavam três folhas definitivas, sendo a primeira completamente expandida, utilizando-se o espaçamento de $1,0 \times 0,30 \mathrm{~m}$. A unidade experimental constou de quatro fileiras de 4,5 m de comprimento, espaçadas 1,0 m, totalizando área de $18 \mathrm{~m}^{2}$. Consideraram-se úteis as duas fileiras centrais, excluindo-se uma planta de cada extremidade. As plantas foram conduzidas na vertical com o auxílio de fitilho preso a dois fios de arame passados na horizontal, um a nível do solo e outro cerca de $1,8 \mathrm{~m}$ de altura. Manteve-se somente uma haste por planta, com frutificação nas ramas secundárias, as quais foram podadas após a emissão da segunda folha. Não houve limitação no número de frutos por planta. As capinas manuais, com auxílio de enxada, as irrigações por gotejamento e o controle fitossanitário, foram realizados de acordo com as necessidades e recomendações para a cultura, segundo Silva \& Costa (2003).
Realizaram-se dez colheitas de frutos entre os dias 27/02 a 11/03/2004, quando eles se apresentavam no ponto de colheita comercial, caracterizado pela mudança de coloração da casca, de verde para amarelo intenso no 'Gold Mine' (Grupo Inodorus) e de verde para verde-amarelado e com camada de abscisão na inserção do pedúnculo já desenvolvida, no 'Fleuron' (Grupo Cantaloupensis) (Menezes et al., 2000). Para avaliação do rendimento de frutos eles foram colhidos de cinco plantas úteis, avaliando-se as seguintes características: produtividade comercial e total de frutos $\left(\mathrm{Mg} \mathrm{ha}^{-1}\right)$; número de frutos comerciáveis por planta e massa média de fruto $\left(\mathrm{kg}\right.$ fruto $\left.^{-1}\right)$. Consideraram-se comerciais os frutos com atributos mínimos de qualidade exigidos pelo mercado consumidor, com a eliminação de frutos que apresentavam os seguintes defeitos: semente solta, ferido, queimado, deformado, brocado, mancha de encosto, amassado, cicatriz, virose e bacteriose (Filgueiras et al., 2000).

Para avaliação dos atributos de qualidade utilizou-se um fruto comercial por repetição, colhido na área útil. Nesses frutos se avaliaram: densidade $\left(\mathrm{g} \mathrm{dm}^{-3}\right)$, estimada pela razão entre a massa fresca e o volume do fruto referente ao deslocamento do volume de água; razão de formato dividindo-se os valores do comprimento pelo diâmetro do fruto; espessura do pericarpo $(\mathrm{cm})$ e massa seca do fruto $(\%$ em relação à massa fresca). A firmeza da polpa $(\mathrm{N})$ foi determinada com penetrômetro modelo FT 327 (3 a 27 lb) equipado com ponteira de $8 \mathrm{~mm}$ de diâmetro, na região equatorial após divisão do fruto, longitudinalmente, realizando-se duas leituras em cada uma das partes. A concentração de sólidos solúveis (\%), foi determinada mediante leitura direta em refratômetro digital modelo PR-100, Palette (Atago Co., LTD., Japão), com compensação de temperatura para $25^{\circ} \mathrm{C}$, obtida pela retirada de uma fatia longitudinal do fruto, seguida de homogeneização da polpa em liquidificador e filtragem em papel de filtro (whatman $\left.\mathrm{n}^{\mathrm{o}} 40\right)$. Obteve-se a acidez titulável $(\%)$ foi obtida por titulação do suco (diluição 1:5) com $\mathrm{NaOH} 0,1 \mathrm{~N}$. A evolução de $\mathrm{CO}_{2}$ e de etileno $\left(\mathrm{mL} \mathrm{CO} \mathrm{kg}^{-1} \mathrm{~h}^{-1}\right.$ e $\mu \mathrm{L} \mathrm{C}_{2} \mathrm{H}_{4} \mathrm{~kg}^{-1} \mathrm{~h}^{-1}$, respectivamente) foi avaliada em frutos colhidos a campo, às 7 horas da manhã, transportados ao laboratório, onde permaneceram armazenados a temperatura de $25 \pm 3{ }^{\circ} \mathrm{C}$ por $1 \mathrm{~h}$; em seguida e nessa mesma temperatura, os frutos foram acondicionados durante $1 \mathrm{~h}$, em recipientes de $10 \mathrm{~L}$, hermeticamente fechados e adaptados com rolha de borracha, por onde foram retiradas alíquotas com auxílio de seringas de $1 \mathrm{~mL}$ do gás liberado pelos frutos no espaço vazio desses recipientes; a alíquota amostrada foi injetada em cromatrógrafo a gás (Model GC - 1413, Shimadzu, Kyoto), equipado com detector TCD e FID para determinação das concentrações de $\mathrm{CO}_{2}$ e de etileno. As temperaturas da coluna (porapak-Q), do injetor e do detector foram de, respectivamente, 50,100 e $135^{\circ} \mathrm{C}$.

Realizaram-se as análises estatísticas utilizando-se o programa SAEG (Sistema de Análises Estatísticas e Genéticas SAEG/UFV). As médias dos tratamentos (ambiente de cultivo) de cada híbrido para as características avaliadas, foram comparadas pelo teste de Tukey a $5 \%$ de probabilidade. 


\section{RESULTADOS E DISCUSSÃO}

Maiores valores de produtividade total e comercial, de massa média do fruto e de número de fruto por planta, para os híbridos 'Gold Mine' e 'Fleuron', foram obtidos nos ambientes Controle e Aluminet ${ }^{\circledR} 30 \%$-O (Tabela 2).

Tabela 2. Valores médios de produtividade de frutos total (PT) e comercial (PC), massa média do fruto (MMF) e número de frutos por planta (NFP) de melão híbrido 'Gold Mine' em cultivo sombreado por diferentes tipos de malha*

\begin{tabular}{|c|c|c|c|c|}
\hline Ambientes & $\begin{array}{c}\text { PT } \\
\left(\mathrm{Mg} \mathrm{ha}^{-1}\right)\end{array}$ & $\begin{array}{c}\mathrm{PC} \\
\left(\mathrm{Mg} \mathrm{ha}^{-1}\right)\end{array}$ & $\begin{array}{c}\text { MMF } \\
(\mathrm{kg})\end{array}$ & NFP \\
\hline \multicolumn{5}{|c|}{ Gold Mine } \\
\hline Controle & $51,60 \mathrm{a}$ & 46,90 a & $1,24 \mathrm{a}$ & $1,26 a$ \\
\hline Aluminet $^{\circledR} 30 \%-0$ & $49,50 \mathrm{a}$ & $42,68 \mathrm{a}$ & $1,23 a$ & $1,16 \mathrm{ab}$ \\
\hline Cromatinet $^{\circledR} 30 \%-0$ & $33,87 \mathrm{~b}$ & $28,12 \mathrm{~b}$ & $0,96 \mathrm{~b}$ & $0,97 \mathrm{~b}$ \\
\hline Sombrite ${ }^{\circledR} 30 \%$ & $28,93 \mathrm{~b}$ & $25,42 b$ & $0,88 \mathrm{~b}$ & $0,97 \mathrm{~b}$ \\
\hline CV (\%) & 10,45 & 10,67 & 9,35 & 11,45 \\
\hline \multicolumn{5}{|c|}{ Fleuron } \\
\hline Controle & $57,12 \mathrm{a}$ & $51,13 a$ & $0,92 \mathrm{a}$ & $1,85 \mathrm{a}$ \\
\hline Aluminet ${ }^{\circledR} 30 \%-0$ & $46,29 a$ & $42,32 \mathrm{a}$ & $0,86 a$ & $1,64 a b$ \\
\hline Cromatinet $^{\circledR} 30 \%-0$ & $24,79 \mathrm{~b}$ & $20,33 \mathrm{~b}$ & $0,72 b$ & $0,94 \mathrm{c}$ \\
\hline Sombrite ${ }^{\circledR} 30 \%$ & $33,03 \mathrm{~b}$ & $29,62 b$ & $0,73 b$ & $1,35 \mathrm{~b}$ \\
\hline CV $(\%)$ & 14,53 & 15,30 & 6,57 & 11,56 \\
\hline
\end{tabular}

* Médias seguidas da mesma letra na coluna não diferem entre si, pelo teste de Tukey a $5 \%$ de probabilidade

O melhor desempenho em produção nesses ambientes podem ser atribuídas aos maiores valores de radiação solar incidente no dossel, especialmente no ambiente Controle, e ao maior equilíbrio entre as temperaturas máximas e mínimas do ar no Aluminet ${ }^{\circledR}$ (Tabela 1), quando comparados com as demais malhas. A disponibilidade de assimilados é fundamental para a fertilização e desenvolvimento dos frutos nos estádios iniciais (frutificação), fato que pode ser observado pelo maior NFP nesses dois ambientes. De acordo com o fabricante das malhas Aluminet ${ }^{\circledR} 30 \%-\mathrm{O}$ e Cromatinet ${ }^{\circledR}$ 30\%-O (Polysack, 2003), a malha Aluminet ${ }^{\circledR}$ apresenta, como vantagem comparativa, fios retorcidos revestidos de alumínio o que fornece, em média, $15 \%$ a mais de luz difusa ao ambiente não comprometendo, em grande magnitude, os processos fotossintéticos.

O ponto de saturação luminoso para o meloeiro está entre 1.000 e $1.200 \mu \mathrm{mol} \mathrm{m}^{-2} \mathrm{~s}^{-1}$ (Kitroongruang et al., 1992). Sob condições tropicais e em dias ensolarados é provável que a redução na radiação solar proporcionada pelas malhas não viesse a prejudicar, e até beneficiar, o processo fotossintético e, consequentemente, a produção de frutos no meloeiro pois a radiação incidente no dossel estaria, mesmo assim, dentro da faixa ótima exigida pela cultura. Entretanto, em condições de dias nublados a redução adicional na radiação solar proporcionada pelas malhas limitaria, em parte, o processo fotossintético e, consequentemente, a produção de fotoassimilados e de frutos. Esta limitação ocorreria em razão da radiação incidente sobre as plantas nesses ambientes cair para valores muito aquém do ponto de saturação luminoso. Esta última situação pode ter ocorrido no experimento uma vez que a insolação média diária foi de apenas $4,47 \mathrm{~h}$, veri- ficada durante os 90 dias de condução do experimento. Esse valor está bem abaixo da insolação média diária observada em região semiárida do nordeste brasileiro, que está em torno de $9 \mathrm{~h}$, a qual é responsável por mais de $90 \%$ da produção de melão no Brasil (Silva \& Costa, 2003).

$\mathrm{Na}$ literatura os resultados referentes aos efeitos do sombreamento na produção das culturas, são variados. Nakansah et al. (1996) obtiveram melhores resultados de massa média e produção de frutos sob condições de alta irradiância $\left[1.200 \mu \mathrm{mol} \mathrm{m} \mathrm{m}^{-2} \mathrm{~s}^{-1}\right.$ (RFA)] e menor temperatura do ar $\left(<33{ }^{\circ} \mathrm{C}\right)$; no entanto, concluíram que, mesmo sob condições de baixa irradiância $\left[600 \mu \mathrm{mol} \mathrm{m} \mathrm{m}^{-2} \mathrm{~s}^{-1}\right.$ (RFA)] a fotossíntese e a produção de frutos foram favorecidas por menores temperaturas do ar. Nishizawa et al. (1998) e Combrink et al. (1995) verificaram que o sombreamento não reduziu a massa média dos frutos de melão quando comparados com o cultivo sob condições de pleno sol. Em melancia, Calatayud et al. (2000) obtiveram maior produtividade sob condições sombreadas [800 $\mu \mathrm{mol} \mathrm{m} \mathrm{m}^{-2} \mathrm{~s}^{-1}$ (RFA)] em comparação com o ambiente em pleno sol [1.800 $\mu \mathrm{mol} \mathrm{m}{ }^{-2} \mathrm{~s}^{-1}$ (RFA)]. Por outro lado, Nishizawa et al. (2000) e de Sang Gyu et al. (2003) notaram que o sombreamento reduziu a massa média e a produção de frutos de melão. Para o híbrido Gold Mine temse verificado produtividades que variam de 26,09 a 34,76 $\mathrm{Mg} \mathrm{ha}^{-1}$ (Medeiros et al., 2007). Para híbridos do grupo Cantalupensis tem-se observado valores entre 21,6 a 48,0 $\mathrm{Mg} \mathrm{ha}^{-1}$ (Medeiros et al., 2006; Charlo et al., 2009).

Os tratamentos não exerceram efeitos significativos sobre os atributos físicos como densidade do fruto, percentagem de massa seca e firmeza da polpa em frutos de melão 'Gold Mine' (Tabela 3), nem quanto à densidade do fruto, razão de formato, firmeza da polpa e liberação de etileno para o melão 'Fleuron' (Tabela 3).

A razão de formato apresentou diferença significativa apenas para 'Gold Mine' cujo maior valor nos frutos produzidos sob condição de pleno sol (controle), comparativamente ao Cromatinet ${ }^{\circledR}$ (Tabela 3). Este comportamento indica que frutos obtidos sob condições de pleno sol são relativamente

Tabela 3. Valores médios de densidade (DENS), razão de formato (RF), massa seca (MS) e espessura do pericarpo (EP) em frutos de melão híbridos Gold Mine e Fleuron em cultivo sombreado por diferentes tipos de malha*

\begin{tabular}{lcccl}
\hline Ambientes & $\begin{array}{c}\text { DENS } \\
\left(\mathbf{g ~ c m}^{-3}\right)\end{array}$ & $\begin{array}{c}\text { RF } \\
\text { Gold Mine }\end{array}$ & $\begin{array}{c}\text { MS } \\
(\%)\end{array}$ & $\begin{array}{c}\text { EP } \\
(\mathbf{c m})\end{array}$ \\
Controle & $0,92 \mathrm{a}$ & $1,51 \mathrm{a}$ & $5,73 \mathrm{a}$ & $3,58 \mathrm{a}$ \\
Aluminet & $0,93 \mathrm{a}$ & $1,42 \mathrm{ab}$ & $5,78 \mathrm{a}$ & $3,38 \mathrm{ab}$ \\
Cromatinet & $0,93 \mathrm{a}$ & $1,33 \mathrm{~b}$ & $5,41 \mathrm{a}$ & $2,95 \mathrm{c}$ \\
Sombrite & $0,94 \mathrm{a}$ & $1,45 \mathrm{ab}$ & $5,22 \mathrm{a}$ & $3,08 \mathrm{bc}$ \\
CV (\%) & 3,62 & 4,94 & 9,13 & 5,85 \\
\hline & & Fleuron & \\
Controle & $0,98 \mathrm{a}$ & $1,06 \mathrm{a}$ & $7,32 \mathrm{a}$ & $3,61 \mathrm{a}$ \\
Aluminet & $0,97 \mathrm{a}$ & $1,06 \mathrm{a}$ & $5,83 \mathrm{ab}$ & $3,21 \mathrm{ab}$ \\
Cromatinet & $0,95 \mathrm{a}$ & $1,05 \mathrm{a}$ & $5,19 \mathrm{~b}$ & $2,88 \mathrm{~b}$ \\
Sombrite & $0,97 \mathrm{a}$ & $1,04 \mathrm{a}$ & $6,12 \mathrm{ab}$ & $2,81 \mathrm{~b}$ \\
CV (\%) & 1,84 & 2,89 & 16,13 & 9,71 \\
\hline
\end{tabular}

* Médias seguidas da mesma letra na coluna não diferem entre si, pelo teste de Tukey a $5 \%$ de probabilidade 
mais alongados que em ambientes sombreados. Pereira et al. (2003) e Chaves et al. (2004) verificaram, sob condições de altas densidades de cultivo no meloeiro e, portanto, com problemas de autossombreamento, que os frutos apresentaram formato menos alongado quando comparados com os do cultivo sob condições de baixa densidade de cultivo; os respectivos autores atribuíram a redução no alongamento do fruto à menor disponibilidade de luz às plantas, o que teria propiciado menor fornecimento de fotoassimilados aos frutos. Ainda de acordo com Valantin et al. (2006), variações no tamanho do fruto podem ser consequência de dois processos: da força do dreno durante a divisão celular e da taxa de crescimento do fruto durante a expansão celular.

Maiores valores de espessura do pericarpo dos frutos foram obtidos no ambiente Controle em relação ao Cromatinet ${ }^{\circledR}$ e Sombrite, para ambos os híbridos não diferindo, entretanto, do Aluminet ${ }^{\circledR}$ (Tabela 3). Concomitantemente, foram colhidos frutos com maior massa média nos ambiente controle e Aluminet $^{\circledR}$ (Tabela 2). Tem-se notado, em melão, relação direta entre espessura do pericarpo e massa média de fruto, em razão do maior acúmulo de fotoassimilados ocorrer na parte comestível (pericarpo) resultando, proporcionalmente, em menor cavidade interna (Long et al., 2004; Queiroga et al., 2008). Acredita-se que esta característica é determinada sobretudo pelo maior número e não pelo tamanho das células que compõem este tecido (Higashi et al., 1999).

No melão 'Gold Mine' se obtiveram menores valores de sólidos solúveis (SS) e de acidez titulável (AT) e maiores valores de $\mathrm{CO}_{2}$ liberados pelos frutos no ambiente Controle em relação ao Aluminet ${ }^{\circledR}$ (Tabela 4). Os menores valores de SS e de AT podem ser atribuídos à grande amplitude térmica verificada no ambiente controle. Na faixa de temperatura de 18 a $33{ }^{\circ} \mathrm{C}$ observa-se melhor desenvolvimento da cultura do meloeiro (Fontes \& Puiatti, 2005); no tratamento Controle, temperaturas mínimas abaixo de $18{ }^{\circ} \mathrm{C}$, ocorridas principalmente durante o período noturno, podem ter dificultado a translocação dos fotoassimilados das folhas (fonte) para os frutos (drenos); por outro lado, temperaturas máximas aci-

Tabela 4. Valores médios de sólidos solúveis totais (SST), acidez titulável (AT), firmeza da polpa (FP), respiração $\left(\mathrm{CO}_{2}\right)$ e etileno em frutos de melão híbridos Gold Mine e Fleuron em cultivo sombreado por diferentes tipos de malha*

\begin{tabular}{|c|c|c|c|c|c|}
\hline Ambientes & $\begin{array}{l}\text { SS } \\
(\%)\end{array}$ & $\begin{array}{l}\text { AT } \\
(\%)\end{array}$ & $\begin{array}{l}\text { FP } \\
\text { (N) }\end{array}$ & $\begin{array}{c}\mathrm{CO}_{2} \\
\left(\mathrm{mg} \mathrm{kg}^{-1} \mathrm{~h}^{-1}\right)\end{array}$ & $\begin{array}{c}\text { Etileno } \\
\left(\mu \mid \mathrm{kg}^{-1} \mathrm{~h}^{-1}\right)\end{array}$ \\
\hline \multicolumn{6}{|c|}{ Gold Mine } \\
\hline Controle & $6,38 \mathrm{~b}$ & $0,10 \mathrm{~b}$ & $54,65 a$ & 229,26 a & $0,38 \mathrm{~b}$ \\
\hline Aluminet & $7,60 \mathrm{a}$ & $0,12 a$ & $49,36 \mathrm{a}$ & $142,01 \mathrm{~b}$ & $0,37 \mathrm{~b}$ \\
\hline Cromatinet & $6,70 a b$ & 0,13 a & $47,56 a$ & $203,85 a b$ & $0,92 a b$ \\
\hline Sombrite & $6,55 a b$ & $0,12 a$ & $43,80 a$ & $178,33 a b$ & $1,13 \mathrm{a}$ \\
\hline CV $(\%)$ & 8,22 & 7,27 & 16,58 & 17,09 & 45,80 \\
\hline \multicolumn{6}{|c|}{ Fleuron } \\
\hline Controle & 10,13 a & $0,08 \mathrm{~b}$ & $15,85 a$ & $382,08 \mathrm{~b}$ & $27,75 a$ \\
\hline Aluminet & $8,03 a b$ & $0,07 \mathrm{~b}$ & $17,24 \mathrm{a}$ & $397,84 \mathrm{~b}$ & $29,36 \mathrm{a}$ \\
\hline Cromatinet & $8,43 a b$ & 0,11 a & $19,05 \mathrm{a}$ & $594,65 a$ & $50,55 a$ \\
\hline Sombrite & $7,75 b$ & $0,07 \mathrm{~b}$ & 16,69 a & $501,74 a b$ & $48,88 \mathrm{a}$ \\
\hline CV (\%) & 12,47 & 10,43 & 19,43 & 19,21 & 29,05 \\
\hline
\end{tabular}

* Médias seguidas da mesma letra na coluna não diferem entre si, pelo teste de Tukey a $5 \%$ de probabilidade ma de $33{ }^{\circ} \mathrm{C}$ podem ter acelerado os processos metabólicos (respiratório) aumentando, consequentemente, o consumo de fotoassimilados, diminuindo a disponibilidade de açúcares solúveis e de ácidos orgânicos para os frutos durante o processo de seu amadurecimento. Este tipo de comportamento é reforçado pela maior liberação de $\mathrm{CO}_{2}$ pelos frutos sob condições de pleno sol, apesar de não ter diferido estatisticamente dos ambientes Cromatinet ${ }^{\circledR}$ e Sombrite $^{\circledR}$ (Tabela 4).

Mitchell \& Madore (1992) verificaram que a exposição de plantas de melão a temperatura de $10{ }^{\circ} \mathrm{C}$ durante $72 \mathrm{~h}$ promoveu o acúmulo de amido, sacarose, glicose, frutose e aminoácidos nos tecidos de folhas-fonte. Esses autores concluíram que efeitos indesejáveis, como redução na qualidade dos frutos durante o amadurecimento sob condições de baixas temperaturas, podem ser atribuídos a alterações no suprimento de fotoassimilados pelas folhas-fonte, aos frutos. Temperatura acima de $33{ }^{\circ} \mathrm{C}$ promove aumento da respiração e acelera o processo de crescimento e amadurecimento do fruto o que pode ter prejudicado o acúmulo de fotoassimilados na forma de açúcares solúveis e ácidos orgânicos. Combrink et al. (1995) também verificaram maior concentração de sólidos solúveis totais em frutos de melão crescidos sob condições sombreadas quando comparados com frutos crescidos sob condições de pleno sol; por terem estendido o estágio de maturação, concluíram que condições que favoreçam maior tempo de acúmulo de fotoassimilados nos frutos ainda na planta são importantes na melhoria de sua qualidade. Ao contrário da maioria dos frutos que armazenam quantidades consideráveis de amido na polpa para, posteriormente, serem convertidas em açúcares, o mesocarpo do melão contém pouca reserva de amido, menor que $1 \%$ (Finger \& Vieira, 2002), razão do aumento insignificante do teor de açúcares após os frutos serem destacados da planta.

Apesar do efeito benéfico do sombreamento sobre a manutenção de níveis equilibrados de temperatura mínima e máxima do ar e de sua benéfica influência sobre o acúmulo de sólidos solúveis totais durante as fases de maturação e amadurecimento dos frutos, tem-se verificado, em vários trabalhos, resultados controversos, como será abordado na sequência, para o híbrido Fleuron.

No 'Fleuron' os valores de SS, de AT e de liberação de $\mathrm{CO}_{2}$ nos frutos não seguiram a mesma tendência verificada no 'Gold Mine' (Tabela 4). Os maiores valores de SS no 'Fleuron' foram obtidos sob condições de pleno sol em relação ao Sombrite, mas não diferindo estatisticamente dos ambientes Aluminet ${ }^{\circledR}$ e Cromatinet $^{\circledR}$ (Tabela 4). Diferentemente do ocorrido com 'Gold Mine', os maiores valores de radiação solar, conjuntamente com os menores valores de UR mínima e máxima do ar (Tabela 1), parecem ter contribuído para a maior concentração de SS em frutos do 'Fleuron' sob condições de pleno sol. Outra evidência da importância da radiação solar e da menor UR do ar para obtenção de concentrações elevadas de SS, é devida à elevada percentagem de massas fresca e seca nos frutos do 'Fleuron' sob condições de pleno sol (Tabelas 2 e 3).

No 'Fleuron' a temperatura do ar parece não ter exercido influência sobre o consumo de açúcares solúveis e ácidos orgânicos. Esta afirmativa está fundamentada na menor libera- 
ção de $\mathrm{CO}_{2}$ pelos frutos sob condições de pleno sol, apesar do mesmo não ter diferido estatisticamente dos ambientes Aluminet $^{\circledR}$ e Sombrite ${ }^{\circledR}$ (Tabela 4). O 'Fleuron' apresenta rendilhamento externo, o que pode permitir trocas gasosas com o ambiente com maior facilidade e ser uma das razões para este comportamento diferenciado. Em condições semiáridas do nordeste brasileiro, onde se verificam altas irradiância e temperatura e baixas UR do ar, tem-se constatado a produção de frutos de melão com elevadas concentrações de sólidos solúveis totais e sabor mais agradável (Silva \& Costa, 2003).

Menores concentrações de açúcares solúveis totais em frutos de melão sob condições de ambiente sombreado foram observadas por Nishizawa et al. (1998) e Nishizawa et al. (2000), concluindo que esta redução se deve principalmente à escassez de fotoassimilados supridos pelas folhas-fonte nesses ambientes. Combrink et al. (1995) verificaram que a UR do ar na precolheita exerce grande influência sobre o teor de SST; frutos de melão mantidos durante 12 dias (antes da colheita comercial dos frutos) sob UR do ar de $22 \%$ apresentaram maior teor de SST $(12,2 \%)$ que quando mantidos sob UR do ar de $89 \%(10,8 \%)$.

A concentração de SS no 'Gold Mine' ficou abaixo do valor mínimo exigido pelos mercados consumidores interno (8\%) e externo (9\%), mesmo sob condições de pleno sol; para o 'Fleuron', somente no manejo adotado como Controle o valor atende às exigências do mercado externo, enquanto sob Sombrite $^{\circledR}$ o valor ficou abaixo do exigido para o mercado interno (Tabela 4). A principal razão para a baixa concentração de SS nos frutos de ambos híbridos, foi o alto índice pluviométrico (Tabela 1), que atingiu $1.027 \mathrm{~mm}$ durante os três meses de cultivo dos meloeiros, inclusive no período de amadurecimento dos frutos. Outros fatores, como a umidade relativa do ar e a baixa insolação média diária (Tabela 1), também podem ter contribuído para os baixos valores de SST dos frutos.

Em regiões semiáridas do nordeste brasileiro, onde o meloeiro é cultivado em maiores proporções, verificam-se valores médios de sólidos solúveis totais entre 10 e12\% em híbridos do tipo Amarelo (Grupo Inodorus) e de 13\% em híbridos do tipo Charentais (Grupo Cantaloupensis) conforme Filgueiras et al. (2000). Para o 'Gold Mine' tem-se verificado valores médios de $7,8 \%$ na concentração de SST quando cultivado no período das chuvas, em Mossoró, RN (Mota et al., 2002). Apesar da região semiárida brasileira apresentar índice pluviométrico médio inferior a $600 \mathrm{~mm}$ ano ${ }^{-1}$, recomenda-se não cultivar o meloeiro no período de chuvas mais intensas que ocorrem entre dezembro e abril, pois as chuvas causam, além de problemas fitossanitários, redução na qualidade dos frutos, principalmente quando as precipitações ocorrem próximo ao período de colheita (Silva \& Costa, 2003).

$\mathrm{O}$ comportamento diferenciado quanto às características de qualidade dos frutos de melões 'Gold Mine' e 'Fleuron', sob condições de pleno sol e sombreadas, também pode estar relacionado à ausência ou presença do efeito climatério, que atua de forma diferenciada sobre alterações fisiológicas, bioquímicas e metabólicas durante o processo de amadurecimento dos frutos. Frutos de melão 'Gold Mine' (Grupo Inodorus) são considerados não-climatéricos, como constatado pela baixa liberação de $\mathrm{CO}_{2}$ e de etileno durante a fase de amadurecimento (Tabela 4). Por outro lado, frutos de melão 'Fleuron' (Grupo Cantaloupensis) são considerados climatéricos por apresentarem alta liberação de $\mathrm{CO}_{2}$ e etileno durante a fase de amadurecimento (Tabela 4). Frutos climatéricos são caracterizados pelo aumento acentuado na respiração e na produção de etileno por ocasião do início do amadurecimento, evidenciado pelo amaciamento da polpa e pelas alterações da cor da casca e da polpa. Em frutos nãoclimatéricos não ocorre aumento na respiração nem na produção de etileno por ocasião do amadurecimento (Finger \& Vieira, 2002).

A liberação de etileno pelos frutos do 'Gold Mine' foi maior nos ambientes Sombrite ${ }^{\circledR}$ em relação ao Controle e Aluminet $^{\circledR}$, apesar de não ter diferido do Cromatinet ${ }^{\circledR}$. No 'Fleuron' não se verificou diferença significativa entre os ambientes com maiores valores absolutos sob Cromatinet ${ }^{\circledR} \mathrm{e}$ Sombrite ${ }^{\circledR}$ (Tabela 4).

O etileno está relacionado com o amaciamento dos frutos. Nishizawa et al. (2000) e Aikawa et al. (2007) observaram que a produção de etileno e a redução da firmeza da polpa em frutos de melão foram aceleradas pelo sombreamento em comparação com às condições não sombreadas. No 'Gold Mine' a firmeza da polpa não seguiu o mesmo comportamento da produção etileno entre os ambientes de cultivo; entretanto, no 'Fleuron' a liberação de etileno pelos frutos e a firmeza da polpa apresentaram o mesmo comportamento entre os ambientes, evidenciando que fatores outros e não apenas o etileno podem estar envolvidos no amaciamento dos frutos em melões não-climatéricos, como o híbrido 'Gold Mine'.

A baixa insolação média diária durante a condução do experimento pode ter mascarado, em parte, os efeitos das malhas sobre a cultura, os quais poderiam ocorrer em maior evidência sob condições de semiárido; mesmo assim, o cultivo do meloeiro sob restrição de luz mostrou-se promissor possibilitando o cultivo desta espécie, tanto em sistemas isolados utilizando-se sombreamento artificial como em sistemas agroflorestais ou em cultivos associados.

\section{CONCLUSÕES}

1. Dentre os tratamentos com sombreamento a malha Aluminet ${ }^{\circledR} 30 \%$-O foi o que mais se destacou, não diferindo em produção nem em qualidade, de frutos do tratamento sob condições de pleno sol.

2. Verificou-se que os fatores climáticos registrados em cada ambiente de cultivo e os fatores genéticos inerentes aos híbridos 'Gold Mine' (Grupo Inodorus) e 'Fleuron' (Grupo Cantaloupensis) interferiram no desenvolvimento dos frutos do meloeiro.

3. A baixa insolação média diária, a moderada RFA e a elevada precipitação pluviométrica registrada durante o experimento, comprometeram a qualidade dos frutos.

4. O bom desempenho do meloeiro sob a malha Aluminet $^{\circledR} 30 \%-O$, com redução de $30,8 \%$ na RFA, abre perspectivas para o cultivo desta espécie em sistemas agroflorestais ou em cultivos associados. 


\section{LITERATURA CITADA}

Aikawa, T.; Nishizawa, T.; Ito, M.; Togashi, M.; Yamazaki, N. Effect of shading treatment on ethylene production and watercore in melon fruit (Cucumis melo). Horticultural Research, v.6, p.283-287, 2007.

Andriolo, J. L. Fisiologia da produção de hortaliças em ambiente protegido. Horticultura Brasileira, v.18, n.2, p.23-33, 2000.

Burger, Y.; Shen, S.; Petreikov, M.; Schaffer, A. A. The contribution of sucrose to total sugar content in melons. Acta Horticulturae, v.510, p.479-485, 2000.

Calatayud, A.; Deltoro, V. I.; Alexandre, E.; Barreno, E. Acclimation potential to high irradiance of two cultivars of watermelon, Biologia Plantarum, v.43, n.3, p.387-391, 2000.

Charlo, H. C. O.; Castoldi, R.; Vargos, P. F.; Braz, L. T. Desempenho de híbridos de melão-rendilhado cultivados em substrato. Científica, v.37, n.1, p.16-21, 2009.

Chaves, S. W. P.; Negreiros, M. Z.; Nogueira, I. C. C.; Pedrosa, J. F.; Bezerra Neto, F.; Pereira, F. H. F. Densidade de plantio na produção e qualidade de frutos em híbridos de melão. Caatinga, v.17, n.1, p.39-45, 2004.

Combrink, N. J. J.; Jacobs, G.; Maree, P. C. J.; Morais, E. M. Effect of relative humidity during fruit development on muskmelon fruit quality. Journal of the Southern African Society for Horticultural Science, v.5, n.1, p.43-46, 1995.

Filgueiras, H. A. C.; Menezes, J. B.; Alves, R. E.; Costa, F. V.; Pereira, L. S. E.; Gomes Júnior, J. Colheita e manuseio pós-colheita. In: Alves, R. E. (ed.). Melão pós-colheita. Brasília: Embrapa Comunicação para Transferência de Tecnologia, 2000. p.23-41.

Finger, F. L.; Vieira, G. Fisiologia pós-colheita de frutos tropicais e subtropicais. In: Zambolim, L. (ed.) Manejo integrado: fruteiras tropicais - doenças e pragas. Viçosa: UFV, 2002. p.1-30.

Fontes, P. C. R.; Puiatti, M. Cultura do melão. In: Fontes, P. C. R. (ed.) Olericultura: Teoria e prática. Viçosa: UFV, 2005. p.407-428.

Higashi, K.; Hosoya, K.; Ezura, H. Histological analysis of fruit development between two melon (Cucumis melo L. reticulatus) genotypes setting a different size of fruit. Journal of Experimental Botany, v.50, n.339, p.1593-1597, 1999.

Kitroongruang, N.; Jodo, S.; Hisai, J.; Kato, M. Photosynthetic characteristics of melons grown under high temperatures. Journal of the Japanese Society for Horticultural Science, v.61, n.1, p.107-114, 1992.

Long, R. L. Walsh, K. B.; Rogers, G.; Midmore, D. J. Source-sink manipulation to increase melon (Cucumis melo L.) fruit biomass and soluble sugar content. Australian Journal of Agricultural Research, v.55, p.1241-1251, 2004.

Medeiros, J. F. de; Silva, M. C. C.; Câmara Neto, F. G.; Almeida, A. H. B.; Souza, J. O.; Negreiros, M. Z.; Soares, S. P. F. Crescimento e produção do melão cultivado sob cobertura do solo e diferentes freqüências de irrigação. Revista Brasileira de Engenharia Agrícola e Ambiental, v.10, n.4, p.792-797, 2006.

Medeiros, J. F. de; de Silva, M. C. C.; Sarmento, D. H. A.; Barros, A. D.de. Crescimento do meloeiro cultivado sob diferentes níveis de salinidade, com e sem cobertura do solo. Revista Brasileira de Engenharia Agrícola e Ambiental, v.11, n.3, p.248-255, 2007.
Menezes, J. B.; Filgueiras, H. A. C.; Alves, R. E.; Maia, C. E.; Andrade, G. G.; Almeida, J. H. S.; Viana, F. M. P. Característica do melão para exportação. In: Alves, R. E. (ed.) Melão póscolheita. Brasília: Embrapa Comunicação para Transferência de Tecnologia, 2000. p.13-22.

Mitchell, D. E.; Madore, M. A. Patterns of assimilate production and translocation in muskmelon (Cucumis melo L.). II. Low temperature effects. Plant Physiology, v.99, n.3, p.966-971, 1992.

Mota, J. K. M.; Menezes, J. B.; Nunes, G. H. S.; Rocha, R. H. C. Qualidade e vida útil pós-colheita do melão Gold Mine produzido na época das chuvas. Revista Brasileira de Produtos Agroindustriais, v.4, n.1, p.23-28, 2002.

Nakansah, G. O.; Maruo, T.; Shinohara, Y. Effects of light and temperature on photosynthetic parameters, yield and fruit quality of watermelon. Japanese Journal of Tropical Agriculture, v.40, n.3, p.118-122, 1996.

Nishizawa, T.; Ito, A.; Motomura, Y.; Ito, M.; Togashi, M. Changes in fruit quality as influenced by shading of netted melon plants (Cucumis melo L. 'Andesu' and 'Luster'). Journal of the Japanese Society for Horticultural Science, v.69, n.5, p.563-569, 2000.

Nishizawa, T.; Taira, S.; Nakanishi, M.; Ito, M.; Togashi, M.; Motomura, Y. Acetaldehyde, ethanol, and carbohydrate concentrations in developing muskmelon fruit (Cucumis melo L. cv. Andesu) are affected by short-term shading. HortScience, v.33, n.6, p.992-994, 1998.

Pereira, F. H. F.; Nogueira, I. C. C.; Pedrosa, J. F.; Negreiros, M. Z.; Bezerra Neto, F. Poda da haste principal e densidade de cultivo na produção e qualidade de frutos em híbridos de melão. Horticultura Brasileira, v.21, n.2, p.191-196, 2003.

Polysack Indústria Ltda. Hortaliças e hidroponia. <http:// www.polysack.com.htm>. 22 Out. 2003.

Queiroga, R. C. F.; Puiatti, M.; Fontes, P. C. R.; Cecon, P. R. Produtividade e qualidade de frutos de meloeiro variando número de frutos e de folhas por planta. Horticultura Brasileira, v.26, p.209-215, 2008.

Sang Gyu, L.; Young Chul, K.; Tae Cheol, S.; Yong Gu, K.; Hyung Kweon, Y.; Hyo Duk, S. Effects of low light intensity after fruit set on growth and quality of oriental melon (Cucumis melo var. Makuwa Makino). Journal of the Korean Society for Horticultural Science, v.44, n.1, p.31-34, 2003.

Schaffer, A. A.; Pharr, D. M.; Madore, M. Cucurbits. In: Zamski, E.; Schaffer, A. A. (ed.) Photoassimilate distribution in plants and crops: source-sink relationships. New York: Marcel Dekker, 1996. p.729-757.

Silva, H. R.; Costa, N. D. Melão produção: Aspectos técnicos. Brasília: Embrapa Informação Tecnológica, 2003. 225p.

Taiz, L.; Zeiger, E. Fisiologia vegetal. 3.ed., Porto Alegre: Artmed, 2004. 719p.

Valantin, M.; Vaissiere, B.E; Gary, C.; Robin, P. Source-sink balance affects reproductive development and fruit quality in cantaloupe melon. Journal of Horticultural Science \& Biotechnology, v.81, p.105-117, 2006.

Villanueva, M. J.; Tenorio, M. D.; Esteban, M. A.; Mendoza, M. C. Compositional changes during ripening of two cultivars of muskmelon fruits. Food Chemistry, v.87, p.179-185, 2004. 